\title{
0 confinamento
}

\section{racial do}

\section{mundo acadêmico}

\section{brasileiro}

JOSÉ JORGE DE

CARVALHO é professor

do Departamento

de Antropologia da

Universidade de Brasília.

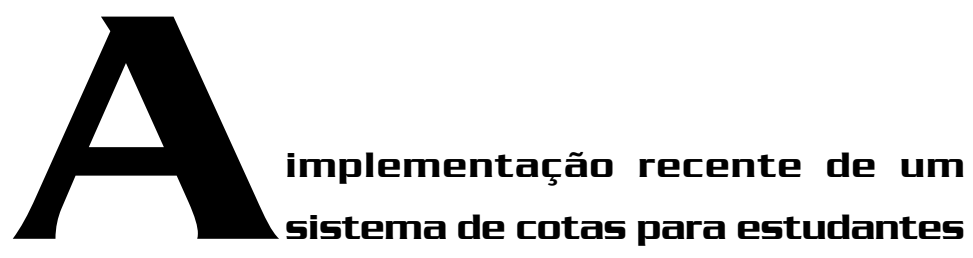
negros no ensino superior é um fenômeno que rompe radicalmente com a lógica de funcionamento do mundo acadêmico brasileiro desde a sua origem no início do século passado. Por um lado, as cotas estão provocando um reposicionamento concreto das relações raciais no nosso meio acadêmico, começando pelo universo discente da graduação, porém com potencial para estender-se à pós-graduação, ao corpo docente e aos pesquisadores. Por outro lado, a polêmica gerada em torno das cotas coloca questóes teóricas e epistemológicas sobre a legitimidade e 0 estatuto de verdade das interpretações das 
relaçães raciais no Brasil formuladas no interior desse universo acadêmico profundamente desigual do ponto de vista racial. Prop̄onho, entấb, eshoçar uma reflexãu sobre as relaçães raciais no Brasil pós-cotas que tome em consideraçãa a condição racial dos té́ricos e aś experiências de interação racial que suscitaram [ou não] as teorias que produziram.

Começo então por afirmar que as teorias e as interpretaçãues das relaç̧áes raciais no Brasil sempre foram elas mesmas racializadas, como conseqüência da distância e doisolamento mútud que tem caracterizado âs relaçóes entre os intelectuais e acadêmicos brancos e os intelectuais e acadêmicos negros. Conforme mostrarei mais adiante, a pretensão de universalidade presente nas formulaçães dos cientistas saciais brancos é questionada quando tomamos em conta a situação de segregação racial extrema do nosso mefí acadêmico. Muitos discursos, antes lidos como inclusivos ao falar de todos os brasileiros na primeira pessaga do plural (uma frase típica de cientistas suciais brancos tem sido: "entre nús" as relaçães raciais sáu diferentes de como são nas Estados Unidos ou na África do Sul], nấ possuem mais a mesmo grau de legitimidade neste momento de revisãa epistemológica radical suscitado pelas propostas de cotas porque silenciaram essa mesma condição de exclusão e de segregação racial que marcallañossa vida universitária até hoje.

Na qualidade de membre dessa academia branca que nunca aceitou falar da sua brancura, também passei uma déccada inteira como docente

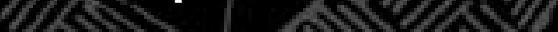
falando do racjsmubrasileiro sem referir-me mais diretamente an racismo acadêmico. Contudo, meu dhar sobre as relaçães raciais no Brasil muadu dramaticamente nos últimos sete anos 
NEELIZMENTE

SOEMOS TRES VAGAS.

Charge da

exposição

"Ser Negro

Hoje”, Museu

Paulista,

out./88 
como conseqüência de um incidente racial ocorrido justamente com um estudante de doutorado de Antropologia da UnB que eu orientava. A crise (pessoal, política e intelectual) gerada por esse caso levou-me inclusive a formular uma proposta de cotas para negros e índios para a UnB, em parceria com Rita Segato ${ }^{1}$. No momento em que o estudante foi reprovado em circunstâncias inaceitáveis, pude dar-me conta de que se tratava do primeiro doutorando negro da história do nosso programa de pós-graduação. Ao deparar-me com essa desconcertante singularidade, o passo seguinte foi averiguar e constatar que essa ausência de estudantes negros é comum a todos os programas de pós-graduação de Antropologia do país e a todos os demais programas de pós-graduação da UnB. A grande revelação subseqüente, porém, surgiu quando fiz para mim mesmo a pergunta que me diz respeito mais diretamente: quantos colegas negros tenho e quantos negros fazem parte do quadro de docentes da UnB?

Após constatar que convivia há mais de uma década com 60 colegas brancos no Instituto de Ciências Sociais da UnB decidi realizar, em 1999, um censo racial informal, com a ajuda de colegas e estudantes negros. Chegamos a uma conclusão que ainda me estarrece: a UnB, que havia sido inaugurada em 1961 com pouco mais de duzentos professores e que, ao longo de quatro décadas, havia ampliado esse número para 1.500 , conta com apenas 15 professores negros. Ou seja, após 45 anos de expansão constante do seu quadro docente, a universidade, que foi concebida como modelo de inovação e de integração do país consigo mesmo e com o continente latino-americano, ainda não absorveu mais que $1 \%$ de acadêmicos negros. Esse número tão baixo nos permite deduzir que mais da metade dos 50 colegiados departamentais da UnB é inteiramente branca, assim como inteiramente brancos são alguns institutos que contam cada um com mais de 100 professores. Dito em termos mais dramáticos, existem áreas da instituição que funcionam na prática, sem que tenha havido até agora nenhum questionamento político ou legal, em um regime de completo apartheid.

Após o censo racial docente na UnB, passei então a solicitar a ajuda dos meus colegas negros para conhecer a porcentagem de docentes negros em outras universidades públicas. Mesmo admitindo uma margem de erro nas amostragens por eles reunidas (e na verdade colocamos um percentual de $20 \%$ acima do número encontrado), deparamo-nos com situações chocantes, como as da USP, Unicamp, UFRJ e UFRGS, instituições em que a proporção de professores negros nãopassa de 0,2\%; a da UFSCAR, de $0,5 \%$ e a da UFMG, de 0,7\%. Dito de outro modo, em nenhuma universidade considerada como referência nacional na pesquisa esse número parece não passar de $1 \%{ }^{2}$. Na verdade, a porcentagem da UnB pode ser avaliada como "muito alta" comparada com as outras universidades de ponta que mencionei. Infelizmente, não existe ainda um censo racial nacional da docência nas universidades públicas e a sua própria inexistência já é um forte indício da resistência da classe acadêmica de enfrentar-se com sua condição racial privilegiada. Contudo, não é difícil fazê-lo, por uma razão muito simples: os poucos docentes negros conhecem muito bem quem são todos os seus (poucos) colegas negros; e justamente porque têm plena consciência de que fazem parte de uma minoria racial, vários deles já realizaram o censo racial informal da classe docente das instituições onde trabalham.

Acredito que essa condição de exclusão racial extrema na docência superior deve ser tomada em conta na hora de refletirmos sobre os modelos de interpretação das relações raciais no Brasil. Paradoxalmente, foi justamente desse ambiente segregado que saíram todas as teorias que negam a existência de segregação racial no Brasil. E se estamos falando de relações raciais, é perfeitamente aceitável que demandemos dos intérpretes não apenas a sua leitura da desigualdade racial existente na sociedade brasileira "lá fora", mas também que se posicionem acerca dessa realidade de segregação de que eles mesmos participam. Está claro que não sairemos "naturalmente" desse escândalo de segregação racial. Já
Esse episódio já foi discutido por vários autores. Ver Alves (2001), Torres (2001), Santos (2003). Pereira (2004), Carvatho (2002 e 2005a) e Segato (2005). Sobre a proposta de cotas da UnB, ver: Carvalho $\&$ Segato (2002).

2 Trabalho aqui coma tabela que preparei no meu livro /Carvalho 2005b). 
ampliamos os números de estudantes e de docentes dezenas de vezes nas últimas décadas, e os números relativos à presença negra em nada melhoraram.

Podemos falar aqui, para não esvaziar a palavra "racismo", de uma situação de confinamento racial vivida por nós, docentes das universidades públicas brasileiras. Se não somos diretamente responsáveis por essa exclusão, nem nos sentimos coniventes com a sua reprodução, então admitamos, pelo menos, para iniciar uma reflexão crítica, que temos sido forçados a desenvolver nossas atividades dentro de um regime de confinamento racial que herdamos das gerações passadas de acadêmicos.

Gostaria de ilustrar essa situação de confinamento racial vivida por todos nós, acadêmicos brasileiros. Se juntarmos todos os professores de algumas das principais universidades de pesquisa do país (por exemplo, USP, UFRJ, Unicamp, UnB, UFRGS, UFSCAR e UFMG), teremos um contingente de aproximadamente 18.400 acadêmicos, a maioria dos quais com doutorado $^{3}$. Esse universo está racialmente dividido entre 18.330 brancos e 70 negros; ou seja, entre $99,6 \%$ de docentes brancos e $0,4 \%$ de docentes negros (não temos ainda um único docente indígena). Se escolhermos aleatoriamente um professor desse grupo, o perfil básico que encontraremos será o seguinte: esse professor (ou professora) foi um(a) estudante branco(a) que teve poucos colegas negros no secundário, pouquíssimos na graduação e praticamente nenhum no mestrado e no doutorado; como aluno(a), sempre estudou com professores brancos. Desde que ingressou na carreira docente faz parte de um colegiado inteiramente branco, dá aulas para uma maioria esmagadora de estudantes brancos na graduação e de $100 \%$ de pós-graduandos brancos. Além disso, os assistentes e colegas do seu grupo de pesquisa são todos brancos. Como conseqüência desse confinamento, em algumas faculdades mais fechadas e elitizadas, é perfeitamente possível que um docente e pesquisador desenvolva por décadas o seu trabalho acadêmico sem conviver jamais com um único estudante negro ou com um único docente negro; quando muito, conviverá com alguns servidores negros, com os quais estabelece relações de pouca ou nenhuma identificação.

Um exemplo desse confinamento certamente ocorreu e ainda ocorre com professores que trabalham em faculdades como o Centro de Ciências da Saúde (CCS), da UFRJ, que conta com cerca de 800 professores, dos quais apenas três são negros; e a proporção de estudantes de Medicina do CCS não é muito diferente da dos docentes. Isso significa que foi possível criar no Brasil, por mais de meio século, instituições de ensino autocontidas e segregadas, e que simultaneamente não estivessem desobedecendo a nenhuma lei nacional que proibisse a segregação racial. Ou seja, a segregação racial no meio universitário jamais foi imposta no Brasil legalmente, mas sua prática concreta tem sido a realidade do nosso mundo acadêmico, através de mecanismos que esse próprio mundo acadêmico tem feito muito pouco por analisar e nem tem mostrado interesse, até recentemente, em desativálos. Fica ainda por compreender qual tem sido a participação do mundo acadêmico na formulação e na implementação prática desses mecanismos institucionalizados de segregação. Dito em outros termos, esse tipo de segregação é apenas reproduzido ou é também produzido no nosso meio acadêmico? A julgar pelo seu caráter generalizado e crônico, provavelmente seja uma soma das duas coisas.

A experiência inversa de confinamento dos poucos professores negros deve ser igualmente ressaltada, pois ela os afeta de um modo muito mais grave que aos docentes brancos. Por exemplo, uma colega negra da UnB trabalha há décadas em um instituto com mais de 100 professores no qual ela é a única negra. A questão racial deveria entrar nos seus temas de trabalho, porém sofre a inibição constante da convivência com os colegas, que se mostram incomodados quando a questão racial aparece explicitamente em alguma discussão sobre os temas de pesquisa de interesse do instituto. O que nunca discutimos em nossos trabalhos é até que ponto estamos dispostos a interpretar 
esses "incômodos" dos acadêmicos brancos frente às necessidades de afirmação racial dos seus colegas negros como manifestações específicas de violência racial. E também nunca questionamos por que essas manifestações de incômodo gozam de impunidade no nosso meio.

Um doutorando da Sociologia contoume o difícil dilema por ele vivido durante a sua entrevista para ingresso no doutorado. No fim da entrevista um dos examinadores, ciente de que o candidato queria estudar relações raciais, perguntou-lhe se ele era militante do Movimento Negro. Ele percebeu claramente que se desse uma resposta afirmativa seria inevitavelmente reprovado. Mentiu, então, afirmando que havia sido militante no passado, mas que agora havia decidido dedicar-se "de fato" à carreira acadêmica. A resposta agradou ao examinador, que finalmente concordou em aprová-lo. Termina agora seu doutorado e obviamente evitará ser examinado por esse professor, conhecido em seu departamento por pregar agressivamente contra as cotas para negros em sala de aula. A lição que aprendeu (e que agora pratica) é que o mundo acadêmico brasileiro é um campo minado para pesquisadores negros e não se pode ser ingênuo, franco ou aberto acerca da questão racial nesse nosso meio.

Casos desse tipo se multiplicam nos depoimentos dos pós-graduandos de $\mathrm{Hu}$ manidades e Ciências Sociais, com quem converso constantemente: sentimento crônico de inadequação, tendência ao disfarce para proteger suas convicções mais profundas, asfixia diante do ambiente inteiramente branco, dificuldade em colocar com franqueza suas posições teóricas sobre as relações raciais no Brasil. E muitas vezes se vêem forçados a ajustar seus temas de pesquisa para não contrariar as posições ideológicas dos seus orientadores sobre esse tema. O que me comentam, de 9 entre 10 pós-graduandos das áreas próximas, é que os professores tendem a censurar os estudos sobre racismo e discriminação racial, influenciando os seus orientandos para que "abrandem" a discussão ou mesmo que a desloquem para outras correlações definidas como mais "amplas" e menos "radicais".

Esse ambiente confinado apresenta sintomas que vão desses mecanismos altamente sofisticados de inibição do discurso sobre o conflito racial até manifestações mais desinibidas dos estereótipos sobre a exclusão negra do espaço acadêmico. Um professor negro contou-me recentemente um episódio constrangedor: deu a primeira aula do semestre de uma disciplina da carreira de Medicina de uma universidade particular carioca para uma turma de 68 alunos com apenas dois negros. Quando entrou na sala dois dias depois, ao começar a segunda aula, alguns dos alunos brancos se surpreenderam e lhe disseram abertamente: "O que você faz aqui?". "Vim dar aula, obviamente", respondeu. "Ah, mas nós pensamos que aquela aula era um trote!"

Um professor negro em um curso de Medicina só pode ser um trote? Como conseguimos construir no Brasil um espaço acadêmico tão poderoso, numeroso e tão excludente? Equais são os mecanismos que acionamos para mantê-lo tão segregado ao longo de quase um século, apesar de tê-lo ampliado constantemente década após década? Em suma, por que os negros não foram incluídos apesar da expansão vertiginosa experimentada pelas instituições superiores de ensino e pesquisa nas últimas cinco décadas? E mais grave ainda, por que nós, cientistas sociais brancos, nunca falamos desse ambiente de confinamento racial em que vivemos?

Há poucos meses um diretor do $\mathrm{CNPq}$ me contava de sua recente viagem a Moçambique, realizada com a finalidade de ajudar o governo moçambicano a montar um Ministério de Ciência e Tecnologia nos moldes do nosso ministério e do CNPq. Dizia ter ficado estarrecido quando descobriu que havia apenas quatro doutores negros em todo o país. Indaguei-lhe por que esse número era tão baixo e me respondeu que os portugueses não permitiam que os africanos cursassem as universidades. Esse diretor tocou aqui, ainda que inadvertidamente, um tema caríssimo a muitos dos nossos teóricos da diferença racial brasileira frente a países como Estados Unidos e África do 
Sul: supostamente, o colonialismo português havia sido mais assimilacionista que o britânico, o belga ou o francês. Perguntei-lhe então se ele tinha uma idéia de quantos pesquisadores negros existem na carreira de produtividade em pesquisa do CNPq. Admitiu que nunca havia pensado no assunto, mas que o número deve ser baixíssimo também - não mais que quatro, possivelmente, por cada uma das grandes áreas do CNPq. E acabava de fazer uma viagem de apoio à assimilação de negros no mundo acadêmico moçambicano, enquanto “entre nós” ainda não conseguimos sequer iniciar uma discussão sobre a necessidade imperiosa de abrir a carreira de docência e pesquisa para negros e índios!

O primeiro passo para qualificar essa discussão é produzir um censo étnico-racial geral de todas as nossas instituições superiores de ensino e pesquisa para produzir em seguida um diagnóstico e uma análise minuciosa da história de cada instituição em busca de indícios da existência de mecanismos que podem ter sido (e provavelmente foram) acionados até hoje para barrar os negros na entrada da docência e da pesquisa. Enquanto não enfrentarmos nossa ignorância não poderemos ir além da mera identificação dos sintomas do confinamento racial acadêmico brasileiro. Atualmente contamos com uma única reitora negra entre os mais de 1.000 reitores do conjunto de universidades públicas e privadas: a reitora da Universidade Estadual da Bahia, que é também a primeira reitora negra da história do estado. Ou seja, em que pese a população de $80 \%$ de negros em Salvador, a UFBA nunca teve um reitor negro. $\mathrm{Na}$ verdade, não sabemos sequer muito bem o número de professores negros da UFBA. Será muito mais que o $1 \%$ que constatamos nas outras universidades acima mencionadas? É fato sabido que a UFMG já teve um reitor negro. Quanto às outras universidades mencionadas, mais de 70 anos de UFRGS, UFPR, USP, UFRJ e de 45 anos de UnB não foram ainda suficientes para que um docente negro chegasse ao posto máximo dessas instituições de ensino superior.

Uma assimilação tão baixa por parte da academia de representantes de um contingente de $45 \%$ da população nacional coloca questionamentos graves para o Brasil, país que abriga a segunda população negra mais numerosa do mundo. Em termos de recusa à assimilação, de confinamento e de segregação racial, nosso mundo acadêmico mais se aproxima à antiga Rodésia e à África do Sul dos anos 50. Afinal, como já o disseram analistas notáveis como Max Gluckman, o mundo acadêmico tende a ser autocontido também em termos de relações sociais, de modo que oconfinamento racial que vivemos extravasa o horário de trabalho na universidade e se estende às demais esferas da vida ${ }^{4}$. Quantos dos 18.400 docentes e pesquisadores brancos das universidades mencionadas interagem com alguma intensidade com negros e negras, em relações minimamente igualitárias, fora da academia, já que convivem apenas com brancos em seus locais de trabalho? Praticamente nenhum deles, pois a classe social a que pertencem os acadêmicos já vive também segregada racialmente em suas residências e em seus locais de sociabilidade básica, tais como comércio, shoppings, restaurantes, livrarias, cinemas, clubes, todos eles ambientes segregados. A rede de sociabilidade geral que nos envolve distancia-nos radicalmente da comunidade negra. Não funciona no nosso meio sequer o modelo freyriano de uma suposta facilidade de entrosamento entre brancos e negros na África portuguesa (e que estaria presente também no Brasil, segundo ele) em contraste com o modelo de segregação zimbabuano e sul-africano.

Meditemos na famosa passagem de Roger Bastide em que fala da experiência de democracia racial em um bonde noturno do subúrbio do Recife cheio de trabalhadores cansados, onde um negro dormia apoiando sua cabeça no ombro de um empregado de escritório $^{5}$. O curioso aqui é que Bastide não conseguiu estabelecer uma conexão entre o que viu naquele bonde carregando gente humilde e o seu mundo cotidiano na USP, inteiramente segregado e excludente racialmente. Se ainda é segregado hoje, como não seria há 50 anos, quando Bastide decidiu empregar a expressão "democra- 
cia racial" para falar do que vira entre as classes populares do Recife quando visitou Gilberto Freyre. Um relance do que era a realidade racial da USP na época desse texto de Bastide pode ser capturado por uma olhada atenta às fotos do livro História da Universidade de São Paulo, de Ernesto de Souza Campos, publicado em 1954.

Em uma centena de pessoas registradas em mais de 30 fotografias sobre as mais diversas áreas de ensino e pesquisa conduzidas na universidade, não encontramos nem um único rostoque pudéssemos identificarcomo de uma pessoa negra, ou mesmo mulata, nem sequer entre os funcionários. Bastide celebrava a "democracia racial" que encontrara nos bondes de subúrbio do Recife sem conectá-la com o apartheid acadêmico em que vivia no interior da Universidade de São Paulo. Também os textos e as imagens do livro de história da Universidade Federal do Paraná, a mais antiga de todas as nossas universidades públicas, descrevem um mundointeiramente branco. Mais do que um comentário ao que era o nosso mundo acadêmico antes, chamo a atenção, através desses livros, sobre como ele se encontra hoje: fotos dessas duas universidades no ano 2000 revelariam duas universidades que mudaram muito pouco na sua composição racial em 70 ou mesmo em 90 anos, apesar de terem mudado em tudo o mais, em termos de crescimento do número de alunos, professores, cursos, laboratórios, instalações.

Essa repetição, sem alarde nem conflito aberto, da brancura extrema das nossas universidades aponta para um fenômeno que ouso chamar de impunidade de segregação: não existe força estatal no Brasil que obrigue as instituições superiores de ensino e pesquisa a implementarem ações de inclusão étnica e racial entre seus alunos, professores e pesquisadores; e também não existe nenhuma lei estatal que permita punir uma instituição pública por insistir na prática da segregação racial. É preciso ponderar sobre a conexão entre esse mundo segregado o os modelos de interpretação das relações raciais no Brasil produzidos por nós, acadêmicos brancos que participamos desse mundo, até agora sem gerar nenhum conflito nem com as autoridades estatais permissivas da continuidade da segregação nem com as comunidades negras e indígenas excluídas do nosso meio.

Apesar das especificidades do modo como é representada, a realidade racial da academia não difere muito da realidade racial vigente em outras áreas da sociedade, mormente no que tange às estratégias utilizadas para a sua reprodução "informal”, que seria uma das características principais do estilo de racismo brasileiro. No caso da academia, os mecanismos mais comumente ativados que acabam por dar continuidade à prática da segregação racial são: a postergação da discussão, o silêncio sobre os conflitos raciais, a censura discursiva quando o tema irrompe e o disfarce para evitar posicionamentos claros. Procura-se, assim, esvaziar ou desarmar os mecanismos de tensão racial do sistema. Para que isso seja possível, é necessário construir uma alta coesão entre os poderosos e lançar mão constantemente de mecanismos repressivos de baixa intensidade e facilmente disponíveis para uma ação intermitente. Desse modo, evita-se definir o estado de conflito étnico e racial como aberto e a situação é apresentada sempre como transitória, em processo de resolução. Assim, o Estatuto do Índio pode circular por 20 anos pelo Congresso Nacional sem jamais ser votado; enquanto isso, o genocídio, a fome, a invasão das terras indígenas continuam fazendo parte da nossa "normalidade" institucional. Igualmente, o Estatuto da Igualdade Racial pode também passar uma década pelos mesmos corredores do Congresso, ser retalhado e domesticado de vários modos para que não sirva de instrumento efetivo de reparação contra nossos séculos de racismo e mesmo assim ainda não ser votado apesar das promessas.

Dando o exemplo de uma situação concreta do nosso meio acadêmico, também a Reitoria da USP instituiu em 1996 um Grupo de Trabalho Institucional para fazer um estudo detalhado da situação étnico-racial da universidade e, a partir daí, formular uma proposta de inclusão racial através de ações afirmativas ${ }^{6}$. Segundome comentaram várias
6 Sobre o Grupo de Trabalho Institucional e seus objetivos, ver a descrição minuciosa em: Munanga, 1996. 
vezes dois membros desse grupo, nenhuma proposta foi encaminhada à Reitoria até agora, apesar de a Comissão continuar existindo no papel. Não deixa de impressionar inclusive que já foram realizados dois censos étnico-raciais, coordenados por eminentes cientistas sociais da instituição, que confirmam a baixa presença de negros em todos os cursos (de fato, a USP consegue ser ainda mais excludente que a UFPR, universidade que tem a fama de "branca"). Enquanto isso, dez anos já se passaram e a principal universidade brasileira deixou crescer ainda mais o seu passivo de exclusão racial, sem nenhuma conseqüência negativa para sua imagem ou prestígio.

Uma conexão histórica que gostaria de ressaltar sobre esse passivo de inclusão racial refere-se ao projeto explicitamente racista que ocorreu no Brasil nas primeiras décadas do século XX, quando houve uma política estatal de destituir as professoras e os professores negros dos cargos de diretores das escolas primárias e técnicas. Conforme o estudo pioneiro de Maria Lúcia Müller, a partir de 1903 começou a diminuir, paulatina e inexoravelmente, a presença de docentes negros no ensino primário e fundamental ${ }^{7}$. Sua conclusão é de que já no início da década de 30 as netas de ex-escravas haviam sido expulsas da profissão de normalistas. A escola pública projetada para formar o espírito da nação se havia tornado praticamente branca através de políticas adotadas pelo Instituto de Educação do Distrito Federal na era Vargas.

O estudo de Müller foi complementado recentemente por Jerry Dávila. Duas fotos em seu livro mostram o estarrecedor trabalho de "limpeza" racial ocorrido nas escolas públicas do Rio de Janeiro; na primeira delas, em 1911, pelo menos a metade das normalistas eram negras; na segunda, de 1946, todas são brancas. Dávila analisa minuciosamente a política de eugenia do governo brasileiro nos anos 30, que interveio no processo de integração dos negros no sistema escolar de modo a branqueá-lo como um caminho à modernidade. Ou seja, quando as universidades cresceram de um clima geral racista que desautorizava a presença negra na educação.

Sintetizando, podemos afirmar com segurança que quando se constituíram as primeiras turmas de universitários no Brasil, nos anos 30, a comunidade negra acabava de ser praticamente expulsa dos cargos de docentes das escolas públicas. $\mathrm{O}$ pouco capital escolar que os negros haviam acumulado após a Abolição da escravidão foi então severamente desfeito, de modo que ficaram com chances mínimas de competir pelo seletíssimo número de vagas abertas nas universidades do Paraná, Rio Grande do Sul, São Paulo e Rio de Janeiro. É um fato histórico, portanto, que a universidade pública no Brasil foi instalada explicitamente sob o signodabrancura. Enquantoesse pressuposto não for criticado e revisado, continuaremos partícipes desse ato racista inicial.

Essa semicausalidade, ou afinidade eletiva entre uma eugenia na escola básica e uma acomodação a um ambiente segregado no ensino superior, coloca ainda uma questão de sociologia do conhecimento que não posso resolver com os dados de que disponho atualmente, mas que gostaria de pelo menos indicar. Se bem é certo que o processo de branqueamento consciente analisado por Müller e Dávila começou já na primeira década do século (anterior, portanto, à implantação das universidades), ele foi formulado por políticos que tiveram acesso ao ensino superior brasileiro na virada do século XIX para o século XX. Em outros termos, a cultura geral racista que expulsou as normalistas e os professores negros das escolas públicas do Brasil perpassava também o imaginário daqueles que trinta anos depois institucionalizaram o nosso ensino superior.

O nosso racismo acadêmico específico, vivo até hoje, não foi apenas conseqüência, então, de um racismo gerado na estabilização da escola básica, mas uma produção combinada de um mecanismo geral de exclusão racial planejado e executado com eficácia e apenas declarado no tempo em relação à eugenia explícita do Instituto de Educação do Rio de Janeiro na década de 20. Acredito que uma reflexão profunda 


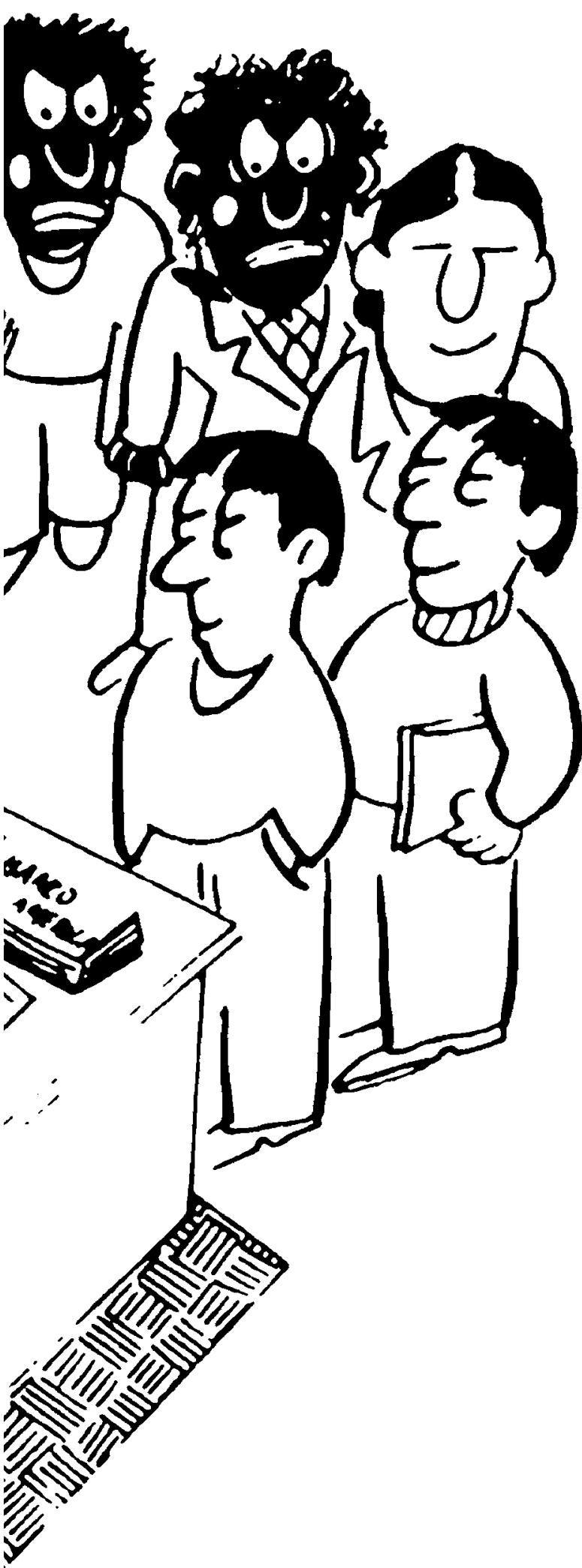

sobre esse momento inicial é absolutamente necessária para entendermos por que somos nós os últimos acadêmicos - provavelmente do mundo inteiro - que ainda resistem a qualquer medida política que force uma integração racial de uma vez por todas nas nossas universidades e instituições de pesquisa. Não há dúvida de que somos um anacronismo no mundoe nem sequer somos capazes ainda de entender exatamente por que demoramos tanto a discutir abertamente esse tema.

Uma vez estabelecida essa conexão, fica ainda uma área nebulosa de semicausalidade entre a exclusão racial via política estatal e uma indiferença, conivência ou mesmo anuência dos acadêmicos face a essa exclusão que continuou mesmo após a morte de Vargas. Tudo se passa como se o mundo acadêmico brasileiro tivesse sido consolidado em cima de uma prática escolar abertamente racista, instalada no Brasil nas primeiras décadas do século e se acomodado a esse racismo sem jamais ter levantado a voz contra ele. Nem sequer a intensidade e o escopo teórico e etnográfico dos inúmeros cientistas sociais de renome que desenvolveram suas pesquisas sobre relações raciais nas universidades de São Paulo, Bahia e Rio de Janeiro desde o início da década de 50 conseguiram produzir um mínimo de reflexividade ou auto-exame: nosso meio continuou imune à presença negra, cativo do confinamento inicial e aparentemente sem manifestar incômodo pela sua brancura quase absoluta.

Uma vez esboçada essa realidade de segregação racial fundante, crônica e pactuada do mundo acadêmico brasileiro, a questão central que me interessa explorar é o significado dos discursos sobre as relações raciais produzidos nesse universo confinado - nossos cientistas sociais certamente expressaram sua rejeição em face do racismo que estudaram na nossa "sociedade", mas não rejeitaram ou questionaram o ambiente racista no qual viveram, pesquisaram e legitimaram como espaço de excelência e mérito. Ou seja, exatamente como sucedeu nos Estados Unidos, foi possível no Brasil desenvolver instituições acadêmicas 
capazes de atender aos altos padrões de excelência científica da modernidade sem perder seu viés de racismo e segregação. A diferença está em que as universidades norte-americanas foram forçadas a se integrar racialmente por decisão do Estado, a partir da década de 60; enquanto isso, as universidades brasileiras continuam segregadas até hoje e a maioria delas ainda resiste à inclusão sustentando-se na ideologia do mérito, mesmo contando com pesquisadores perfeitamente capazes de fazer a crítica das bases econômicas, sociais, políticas e raciais dessa ideologia.

Atualizo aqui o argumento que desenvolvi no meu ensaio "Mestiçagem e Segregação”, escrito no ano do centenário da Abolição, em que eu perguntava se o racismo da segregação explícita não seria derrotado mais rápido que o nosso, da segregação prática e não discursiva (Carvalho, 1988). Com efeito, logo no início dos anos 90 o mundialmente abominável regime do apartheid colapsou e um processo amplo de integração racial e reconciliação nacional foi posto em marcha. É impressionante que o processo da África do Sul não tenha provocado nenhum movimento de autocrítica nos nossos cientistas sociais brancos defensores da diferença racial brasileira. Afinal, o país da mestiçagem continua segregado até hoje enquanto o país do apartheid já avançou nas suas políticas de igualdade racial, inclusive no meio acadêmico.

É claro que esse paradoxo entre modernidade e racismo não está resolvido também nos países ditos "centrais”, como o coloca muito bem, por exemplo, Zygmunt Bauman em sua obra sobre o Holocausto (Bauman, 1998). Um exemplo impressionante dessa resistência do racismo acadêmico a não desaparecer é a história da corporação IBM, contada com dramatismo e minúcia por Edwin Black no livro IBM e o Holocausto (Black, 2001). Durante os anos cruciais do genocídio nazista contra os judeus e outros povos, os campos de concentração eram administrados pelos cartões IBM, precursores do moderno computador. Para tanto, era necessário que funcionários da IBM viajassem todos os meses dos Estados
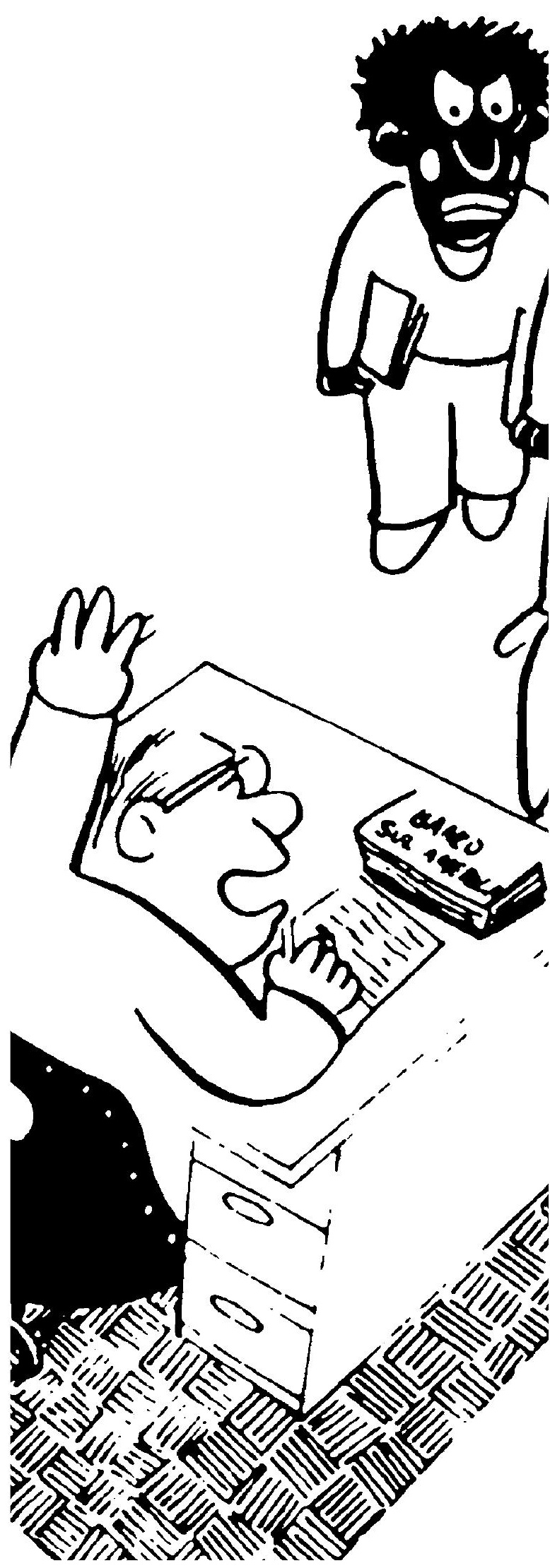
Unidos para Auschwitz e outros campos com a finalidade de instalar os cartões previamente adaptados às demandas de adaptação e extermínio. O mais estarrecedor, porém, dessa cultura acadêmica racista é que a IBM continuou operando após o fim do III Reich sem jamais ter recebido qualquer repúdio ou censura... até hoje, na verdade. Ou seja, grandes pesquisadores das grandes universidades norte-americanas desenvolveram e ainda desenvolvem conhecimentos "científicos" para a IBM inteiramente indiferentes ao massacre que a companhia ajudou a viabilizar e a acelerar quando ensinou os nazistas a utilizarem os seus cartões. Esse caso norte-americano é evidentemente muito mais condenável que o nosso racismo acadêmico, mas a lógica de funcionamento, de uma ciência confinada, monorracial ou monoétnica que não se questiona sobre a sua participação ou conivência com a segregação ou o extermínio, é basicamente a mesma. As tradições acadêmicas britânica e francesa viveram (e ainda vivem) esse mesmo duplo vínculo entre uma visão liberal do saber e uma prática de colaboração ou permissividade com o racismo colonialista na África, na Ásia, no Oriente Médio, no Caribe, na Oceania, etc.

Considero importantíssima a retomada de Maria Lúcia Müller e Jerry Dávila desse período de branqueamento sistemático e consciente porque ela nos permite rever uma ideologia muito difundida por muitos de nossos intelectuais de que fomos diferentes dos países anglo-saxões. Na verdade, não fomos tão diferentes na primeira metade do século XX; e se somos diferentes e isolados agora é por uma razão nada recomendável: porque nos negamos a enfrentar a nossa herança racista. A Sociedade Brasileira de Eugenia operava, na mesma época, de um modo muito similar a como se operou nos Estados Unidos com as campanhas de eugenia que conduziram à esterilização de quase um milhão de pessoas, tal como foi narrado recentemente, com farta documentação, pelo mesmo Edwin Black, no seu livro A Guerra contra os Fracos (Black, 2003). Essa mesma patologia branqueadora foi desenvolvida na Austrália contra os aborígines e seus descendentes através dos planos oficiais de confinamento e segregação racial magistralmente narrados no filme Geração Roubada (Rabbit-ProofFence), de 2002, dirigido por Phillip Noyce, o qual foi baseado na vida real de três jovens mestiças aborígines que, nos anos 30, fugiram de um campo de concentração para não-brancos no deserto australiano.

Dois pontos me interessa ressaltar aqui: por um lado, lembrar aos nossos colegas, cientistas sociais brancos contrários às cotas, que o Brasil também fez parte do grande processo de racialização inferiorizante dos negros ou não-brancos durante pelo menos meio século. O resultado dessa política arianizante iniciada na década seguinte após a Abolição da escravatura e que durou até os anos 40 foi a expulsão, da escola e da carreira de educador, de milhares de negros. Uma desvantagem escolar concreta, portanto, foi promovida pela nossa elite branca racista na primeira metade do século XX. Em segundo lugar, a ideologia da democracia racial, que celebrou a nossa mestiçagem, não teve como plataforma política restaurar ou promover uma igualdade racial no sistema escolar - nem sequer no primário, o que dirá então no superior. $\mathrm{E}$ os ideólogos da democracia racial, em vez de solidarizar-se com os negros que denunciavam o racismo da época, foram hostis à Frente Negra Brasileira.

Foi nesse clima que as universidades se constituíram como espaços institucionais brancos. Elas expandiram seus contingentes de alunos e professores inúmeras vezes ao longo do século XX, mas não tomaram nenhuma iniciativa para corrigir a exclusão racial que as caracteriza desde sua fundação. Ou seja, havia uma política abertamente racista na hora de iniciar a distribuição dos benefícios do ensino superior; todavia, não houve nenhum protesto ou ação antiracista posterior por parte dos acadêmicos brancos contra os privilégios que receberam em virtude desse racismo estrutural. Pelo contrário, houve grande hostilidade e rejeição à presença de vários quadros negros importantes nos postos docentes. Conforme 
expliquei em outro trabalho, nem Guerreiro Ramos nem Édison Carneiro conseguiram entrar na Universidade Federal do Rio de Janeiro; Clóvis Moura também ficou fora das universidades públicas doestado de São Paulo; Pompílio da Hora, erudito professor do Colégio Pedro II, foi recusado duas vezes de entrar na carreira diplomática descaradamente por sua condição racial; e Abdias do Nascimento somente foi professor nos Estados Unidos e na Nigéria como consequiência do seu exílio durante os anos da ditadura; ao regressar ao Brasil, nunca foi acolhido por nenhuma universidade pública, enquanto a maioria dos acadêmicos brancos exilados conseguiu retomar seus postos anteriores ou foram relocados em outros ${ }^{8}$. O resultado dessa segregação racial que já atravessou quatro gerações de universitários é uma prática, quase nunca submetida à crítica, dos acadêmicos brancos falarem sempre entre brancos pretendendo falar por todos e para todos.

A falta de reação por parte dos acadêmicos brancos contra o clima segregado das nossas universidades deve ser entendida no contexto da internacionalização das nossas carreiras. A partir dos anos 70, uma boa parte dos professores passou períodos nos Estados Unidos e na Europa e acompanhou os grandes processos de dessegregação norte-americana, da luta contra o apartheid na África do Sul e da descolonização dos países africanos discutida na Europa. Contudo, nossa classe acadêmica regressava sempre ao mesmo mundo racialmente segregado que habitamos sem esboçar a menor reação. Antropólogos com quem conversei contaram sobre seus interessantes encontros, nos anos 70 e 80 , com negros e índios em Harvard, Colúmbia, Chicago,

Guerreiro Ramos narrou suas amarguras com a academia no Brasil em uma entrevista concedida a Lucia Lippi Oliveira (1995); a expectativa e o fracasso de Edison Carneiro são contados em vários números do jornal Quilombo(2003); Pomp lio da Hora contou os episódios de discriminação racial aberta que sofreu na entrevista que con cedeu a Haroldo Costa (1982) eAbdias do Nascimento narrou as perseguições que sotreu do governo brasileiro em sua obras (Nascimento, 2002). militar não suportava nenhum discurso anti-racista e qualquer denúncia contra o racismo era entendida como infiltração comunista. Em uma palestra proferida no segundo semestre de 1995 na Universidade Federal Fluminense em Niterói, Carlos Hasenbalg ofereceu a seguinte resposta a uma pergunta sobre os estudos das relações raciais na nossa academia:

"Há vinte anos eram muito poucas as pessoas trabalhando esse tema. Eu tive medo de publicar o meu livro em 1979. Dez anos antes, Florestan Fernandes tinha sidoexpulso da USP, aposentado compulsoriamente. Durante todo esse período não se falou nada no país sobre relações raciais. Depois que Florestan publicou A Integração do Negro na Sociedade de Classes, em 1965, e em 72 publicou $O$ Negro no Mundo dos Brancos, a produção na ótica sociológica era ínfima, as condições políticas não eram propícias. A Antropologia, sim, continuou estudando o candomblé, a umbanda, que não eram coisas tão "perigosas" (Hasenbalg, 1998, p. 36).

É verdade que foi intensa a perseguição contra os líderes do Movimento Negro Unificado no final da década de 70. Contudo, muitos cientistas sociais brancos enfrentaram o regime autoritário nos anos 80 até a anistia e o processo de redemocratização com a Nova República. Em suma, houve luta dos brancos contra o autoritarismo, mas não contra o racismo: segregados do mundo acadêmico, os negros não parecem ter contado com muitos aliados brancos no interior da academia. Penso que essas distâncias devem ser tomadas em conta para entender por que avançamos tão pouco na inclusão racial nas últimas décadas em que a segregação racial foi tão questionada nos países supostamente "piores" que o nosso (Estados Unidos e África do Sul).

Esse confinamento é especialmente problemático para as ciências sociais, que pretendem explicaropaís para todos. Asituação mais comum, até agora, nos cursos de Sociologia, Antropologia, Ciência Política, História é que professores e alunos brancos discutam os modelos de relações raciais 
formulados por autores brancos, partindo do princípio de que esses modelos e interpretações falem da "sociedade brasileira". Que esses discursos representem apenas a "visão branca" da sociedade brasileira até agora não tem sido colocado por quase nenhum de nós. Estamos no limiar de uma crise de representação nas ciências sociais e o esforço que temos feito na Universidade de Brasília desde 1988, a partir da crise racial acima mencionada e da luta pela implementação das cotas para negros e índios, é justamente no sentido de discutir essa crise como conseqüência do confinamento racial em que vivemos.

Posso ilustrar essa crise de representação com o censo racial informal que realizamos na Associação Brasileira de Antropologia (ABA) de 2000 em Gramado. De 1.500 participantes, contamos a presença de apenas 15 negros (o mesmo $1 \%$ do número de professores negros). Isso significa que seja o que se tenha discutido sobre relações raciais naquela reunião (e foi muito pouco) foi discutido entre brancos. Os antropólogos brancos, porém, ali presentes, não aceitam que tenham feito uma discussão "branca" da sociedade brasileira, mas simplesmente uma discussão antropológica-os acadêmicos negros evidentemente não acreditam na pretensa neutralidade axiológica dessa discussão e interpretam a ausência de negros na ABA como um sintoma dessa ausência de neutralidade.

Parafraseando o conceito de exotopia, ou extraposição de Mikhail Bakhtin, sugiro que o teste de verdade desse discurso branco somente possa surgir se introduzirmos uma exotopia racial: o grupo racial enfrentado deve necessariamente reagir às formulações do grupo racial hegemônico. Bakhtin inventou o termo "exotopia" para enfatizar a posição de vantagem do intérprete, dentro de uma perspectiva dialógica; nos casos em que aplicou o termo, defendeu a lucidez da extraposição na perspectiva do observador, ou do outro frente ao que enuncia o discurso. Podemos agora inspirar-nos na sua teoria e sugerir que, para casos como o nosso, de discursos ineludivelmente racializados, um dos topoi (lugares) ou posições de atribui-

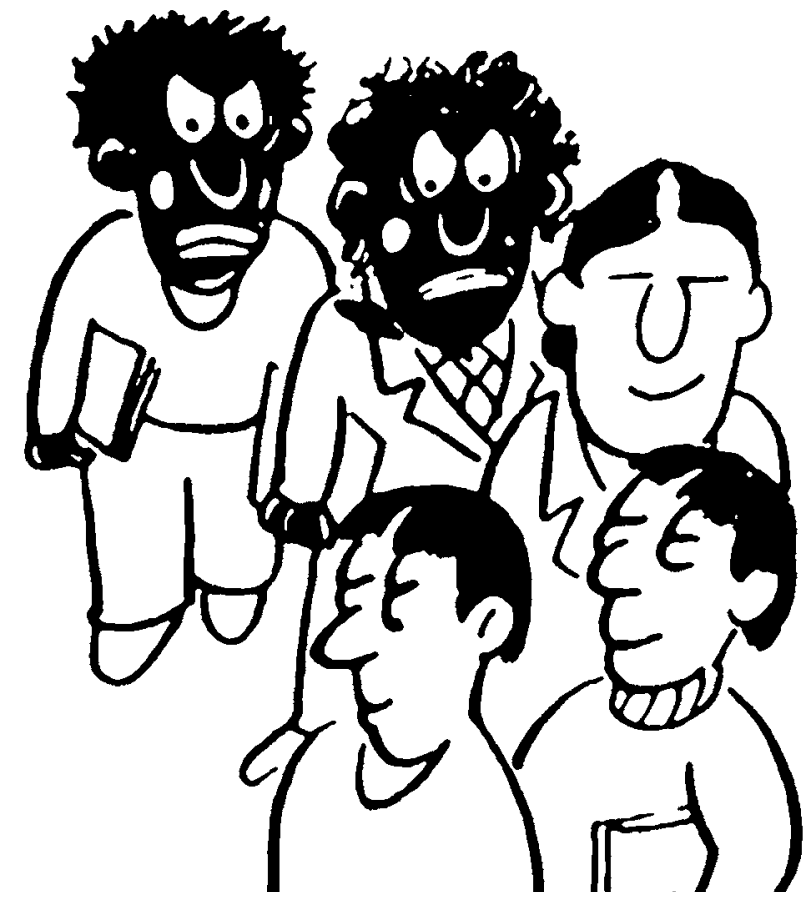

ção de sentido ao discurso do outro seja a posição racial. O contexto que analisamos está racializado pela própria constituição excludente da instituição acadêmica; e onde há exclusão, a extraposição assume um contorno crítico que extravasa a idéia de uma dialogia academicamente neutra. Podemos quase ler a dimensão racial na frase de Bakhtin, que fala do sujeito corporificado: "Nem sequer o seu aspecto exterior o homem pode ver e compreender autenticamente, na sua totalidade, e nenhum espelho nem as fotografias podem ajudá-lo. Sua verdadeira aparência só a podem ver e compreender as outras pessoas, graças à sua localização extraposta no espaço e graças ao fato de serem outros" (Bakhtin, 1982, p. 352).

O ideário das cotas, que apenas começam na graduação, aponta para questionamentos teóricos e metodológicos muito mais densos e amplos do que possam parecer à primeira vista. A ideologia da mestiçagem, por exemplo, tão difundida nas ciências sociais brasileiras, é uma teoria cara aos acadêmicos brancos; já os acadêmicos negros não se identificam com ela e a maioria deles vê o discurso da mestiçagem como parte de uma ideologia racista que visa a desautorizar e a desarmar a afirmação de uma negritude. E sem negritude não há demanda por reparação dos danos causados aos atuais descendentes negros após séculos de escravidão. 
O mesmo argumento vale para a idéia de democracia racial. Vários acadêmicos brancos admitem que a democracia racial não existe, mas ainda assim defendem a importância de salvar o mito. Até onde sei, não há um só acadêmico negro atualmente que queira salvar o mito da democracia racial. Aconsequiência dessa situaçãoé óbvia: democracia racial passa a ser, atualmente, um discurso racializado, criado e mantido pela elite branca brasileira - não é um mito nacional, portanto, e sim um mito do grupo racial dominante, questionado profundamente pelo grupo racial subalterno.

Essa crise de representação indica que enfrentaremos a partir de agora configurações que apontam para uma incomensurabilidade discursiva. Por exemplo, os acadêmicos brancos não aceitam racializar o seu campodiscursivo, mesmoquando transitam sozinhos por esse espaço segregado. Essa negação da racialização é inaceitável para os negros que argumentam que a segregação vivida pelos brancos é o resultado mais visível de uma sociedade profundamente racializada. Os negros se vêem comonegros e vêem os brancos como brancos; os brancos não se dizem brancos (muito menos se vêem falando como brancos) e evitam classificar os não-brancos de negros - a não ser que os não-brancos sejam índios.

A partir de agora, ninguém poderá pretender falar por "nós", brasileiros, sobre a situação racial do país sem se colocar como parte de um campo marcado racialmente. Antes de pensar, portanto, na polarização de valores e de políticas frente à desigualdade racial, quero enfatizar que o que caracteriza a crise de representação provocada pelas cotas é a inevitabilidade dos posicionamentos. A primeira crise que estamos vivendo, então, como intérpretes das relações raciais no Brasil, é a crise da desneutralização racial do campo acadêmico. Esse campo, antes decretado como desracializado, deverá ser visto como racializado por um bom tempo - quem sabe, enquanto durar o processo de dessegregação das nossas universidades (processo que se inicia agora, por enquanto, somente através da política de cotas).

Teremos que aprender a conviver com a marca racial branca, o que não é nada de novo para nossos colegas negros, que sempre conviveram com sua marca racial negra. Os cientistas sociais brasileiros brancos nunca se viram como parte de um campo de confronto racial, embora muitos tenham se visto, com orgulho inclusive, como parte de um campo de confronto de classe. Até recentemente, eles jamais se construíram como passíveis de serem confrontados por um intelectual negro. O único campo em que se admitia o confronto de posições era justamente um campo que foi definido como desracializado ou neutro do ponto de vista da identidade racial, que é o campo da teoria. A primeira crise epistemológica provocada pelas cotas é questionar a neutralidade racial do campo teórico. Esse questionamento é obviamente conhecido da geração presente de cientistas sociais brasileiros através dos escritos de Stuart Hall, Homi Bhabha, Edward Said - e já havia sido colocado há meio século por Guerreiro Ramos, que foi silenciado e esquecido no nosso meio acadêmico, havendo exercido a exotopia racial no seu ensaio "Patologia Social do 'Branco' Brasileiro”, que ainda hoje deve ser celebrado como um dos primeiros exercícios de ciência social conscientemente racializada no Brasil (Ramos, 1995).

Finalmente, acredito que a crise de representação que vivemos oferece também uma oportunidade para renovação teórica e formulação de propostas de inclusão étnica e racial. Mas isso só será possível se admitirmos que a academia contribuiu, no Brasil, para a produção e a reprodução do nosso quadro de desigualdade étnica e racial, o qual não melhorou apesar dos investimentos maciços do Estado no ensino superior ao longo de toda a segunda metade do século passado. Dito de outro modo, a nossa classe de cientistas sociais que discutimos relações raciais está totalmente imersa no problema da desigualdade racial; na verdade, nossas universidades e nossa classe docente têm sido parte do problema racial brasileiro. E acredito sinceramente que somente a partir do momento em que nos enxergarmos como parte do problema poderemos passar a fazer parte da sua solução. 


\section{BIBLIOGRAFIA}

ALVES, Arivaldo Lima. "A Legitimação do Intelectual Negro no Meio Acadêmico Brasileiro: Negação de Inferioridade,

Confronto ou Assimilação Intelectual?", in Afro-Ásia, no 25-26, 2001, pp. 281-312.

BAKHTIN, Mikhail. Estética de la Creación Verbal. Madri, Siglo Veintiuno, 1982.

BAUMAN, Zygmunt. Modernidade e Holocausto. Rio de Janeiro, Jorge Zahar, 1998.

BLACK, Edwin. IBM e o Holocausto. Rio de Janeiro, Campus, 2001.

. A Guerra Contra os Fracos. São Paulo, A Girafa, 2003.

CAMPOS, Ernesto de Souza (org.). História da Universidade de São Paulo. 2a ed. São Paulo, Edusp, 2004 (1954).

CARVALHO, José Jorge. "Mestiçagem e Segregação", in Revista Humanidades, ano V, no 17, 1988, pp. 35-9.

. "Exclusão Racial na Universidade Brasileira: um Caso de Ação Negativa", in Delcele Queiroz (org.). 0

Negro na Universidade. Salvador, Novos Toques, 2002, pp. 79-99.

. "Usos e Abusos da Antropologia em um Contexto de Tensão Racial: o Caso das Cotas para Negros na

UnB", in Horizontes Antropológicos, no 23, Porto Alegre, 2005a, pp. 237-46.

Inclusão Étnica e Racial no Brasil. São Paulo, Attar Editorial, 2005b.

COSTA, Haroldo. Fala, Crioulo. Rio de Janeiro, Record, 1982.

DÁVILA, Jerry. Diploma of Whiteness. Race and Social Policy in Brazil, 1917-1945. Durham, Duke University Press, 2003.

GLUCKMAN, Max. "Les Rites de Passage", in Essays on the Ritual of Social Relations. Manchester, Manchester Univer-

sity Press, 1962.

GUIMARÃES, Antônio Sérgio Alfredo. Classes, Raça e Democracia. São Paulo, Editora 34, 2002.

HASENBALG, Carlos. "Relações Raciais no Contexto Nacional e Internacional", in Estudos e Pesquisas, vol. 4: Racismo. Niterói, Eduff, 1998, pp. 9-41.

MAIO, Marcos Chor \& SANTOS, Ricardo Ventura. “Política de Cotas Raciais, os 'Olhos da Sociedade' e os Usos da Antropologia: 0 Caso do Vestibular da Universidade de Brasília (UnB)", in Horizontes Antropológicos. ano 11, no

23, jan.jun./2005, pp. 181-214.

MÜLLER, Maria Lúcia. "Professoras Negras no Rio de Janeiro: História de um Branqueamento", in lolanda de Oliveira

(org.). Relaçães Raciais e Educação. Rio de Janeiro, DP\&A, 2003, pp. 73-106.

NASCIMENTO, Abdias. O Brasil na Mira do Pan-Africanismo. Salvador, EDUFBA/Ceao, 2002.

OLIVEIRA, Lúcia Lippi. A Sociologia do Guerreiro. Rio de Janeiro, Editora da UFRJ, 1995.

PEREIRA, Pedro Paulo Gomes. "Ruídos na Antropologia: o Caso Ari como Sintoma”. Comunicação apresentada no GT

Antropologia e o Controle do Imaginário, na XXIV Reunião de Antropologia, em Recife, junho de 2004.

QUILOMBO - Jornal dirigido por Abdias do Nascimento. Edição fac-similar. Rio de Janeiro, Editora 34, 2003.

RAMOS, Guerreiro. "Patologia Social do 'Branco' Brasileiro", in Introdução Crítica à Sociologia Brasileira. Rio de Janei-

ro, Editora da UFRJ, 1995, pp. 140-215.

SANTOS, Sales Augusto. "Aç̃o Afirmativa e Mérito Individual", in Iolanda Oliveira \& Petronilha Gonçalves (orgs.).

Identidade Negra. Pesquisas sobre o Negro e a Educação no Brasil. Rio de Janeiro, Anped, 2003, pp. 17-36.

SEGATO, Rita. "Em Memória de Tempos Melhores", in Horizontes Antropológicos, no 23, 2005, pp. 273-82.

SIQUEIRA, Carlos Henrique Romão. "0 Processo de Implementação das Ações Afirmativas na Universidade de Braślia

(1999-2004)", in O Público e o Privado, Revista Acadêmica do Mestrado em Poĺtitcas Públicas e Sociedade, vol.

2, o 2, Fortaleza, UECE, 2004 (no prelo).

TORRES, João Batista de Miranda. "A Televisão a Cabo no Brasil: Pretexto ou Desafio à Ação e ao Pensamento Crítico

da Antropologia". Comunicação apresentada ao Seminário Temático: Antropologia e Comunicação, na XXV Reunião

Anual da Anpocs. Paper incluído no CD-Rom da XXV Anpocs, outubro de 2001. 